\title{
Development, Validation, and Re-selection of Wheat Lines with Pyramided Genes Yr64 and Yr15 Linked on the Short Arm of Chromosome 1B for Resistance to Stripe Rust
}

Yanmin Qie, Center for Agricultural Resources Research, Institute of Genetics and Developmental Biology, Chinese Academy of Sciences, Shijiazhuang, Hebei 050021; University of Chinese Academy of Sciences, Beijing, 100049, China; and Department of Plant Pathology, Washington State University, Pullman, WA 99164-6430; Yan Liu and Meinan Wang, Department of Plant Pathology, Washington State University, Pullman, WA 99164-6430; Xing Li, College of Plant Protection, Hebei Agricultural University, Baoding, Hebei 071001, China and Department of Plant Pathology, Washington State University, Pullman, WA; Deven R. See, USDA-ARS, Wheat Health, Genetics, and Quality Research Unit, Pullman, WA 99164-6430; Diaoguo An, ${ }^{\dagger}$ Center for Agricultural Resources Research, Institute of Genetics and Developmental Biology, Chinese Academy of Sciences, Shijiazhuang, Hebei 050021, China; and Xianming Chen, ${ }^{\dagger}$ USDA-ARS, Wheat Health, Genetics, and Quality Research Unit, Pullman, WA 99164-6430

\begin{abstract}
Stripe rust, caused by Puccinia striiformis f. sp. tritici (Pst), is one of the most destructive diseases of wheat worldwide. The disease is most preferably managed by developing and growing cultivars with highlevel, durable resistance. To achieve high-level and long-lasting resistance, we developed a wheat line, RIL-Yr64/Yr15, by pyramiding Yr64 and $\mathrm{Yr} 15$, both on the chromosome 1BS and providing high resistance to all tested Pst races. To validate RIL-Yr64/Yr15 possessing both genes, we crossed it to Avocet $\mathrm{S}$ (AvS). The $\mathrm{F}_{4}$ RILs from this cross were phenotyped with Pst races under controlled greenhouse conditions and also under natural Pst infection in the field. The population

was genotyped with SSR markers previously reported to be linked to the resistance gene loci and with additional SSR and SNP-KASP markers along chromosome 1B. Both phenotype and genotype data confirmed the copresence of $Y r 64$ and $Y r 15$ in RIL-Yr64/Yr15, and the high-resolution linkage map dissected the chromosomal regions and traced their origins. New lines possessing these genes were selected from the $\mathrm{F}_{5}$ population of cross AvS $\times$ RIL-Yr64/Yr15 by marker-assisted selection. These lines with the two highly effective genes should be more useful than individual gene lines for developing high-level, durable resistant wheat cultivars.
\end{abstract}

As an important food source for human nutrition, both common wheat (Triticum aestivum $\mathrm{L}$., $2 \mathrm{n}=6 \mathrm{x}=42$; AABBDD) and durum wheat (T. turgidum L. subsp. durum [Desf.] Husn.; $2 \mathrm{n}=4 \mathrm{x}=28$; $\mathrm{AABB})$ are widely grown in the world. Wheat crops are continually threatened by stripe rust (yellow rust), caused by the obligate biotrophic fungus Puccinia striiformis Westend. f. sp. tritici Erikss. (Pst) worldwide (Chen and Kang 2017; Wellings 2011). Because of the genetic diversity and rapid adaptation of virulent $P$ st races, the disease occurs almost every year in the areas where climatic conditions

${ }^{\dagger}$ Corresponding authors: X. M. Chen, E-mail: xianming.chen@usda.ars.gov; and D. G. An, E-mail: andiaoguo@163.com

Yanmin Qie and Yan Liu contributed equally to this study.

Funding: This study was supported by the U.S. Department of Agriculture, Agricultural Research Service (USDA-ARS) (Project No. 2090-22000-01800D), Washington Grain Commission (Projects 13C-3061-5682), Vogel Foundation (Project No. 13Z-3061-6665), Idaho Wheat Commission (13C3061-4232), and Department of Plant Pathology, College of Agricultural, Human, and Natural Resource Sciences, Agricultural Research Center, HATCH Project Number WNP00461, Washington State University, Pullman, WA 99164-6430, USA. The China Scholarship Council scholarship to Yanmin Qie is greatly appreciated.

Mention of trade names or commercial products in this publication is solely for the purpose of providing specific information and does not imply recommendation or endorsement by the U. S. Department of Agriculture. USDA is an equal opportunity provider and employer.

*The $\boldsymbol{e}$-Xtra logo stands for "electronic extra" and indicates that three supplementary tables are published online.

Accepted for publication 26 June 2018

This article is in the public domain and not copyrightable. It may be freely reprinted with customary crediting of the source. The American Phytopathological Society, 2019. and cropping systems are favorable for stripe rust (Chen 2005). Based on the experimental data of wheat production, stripe rust can cause yield losses on susceptible varieties ranging from $3 \%$ to more than $90 \%$ (Chen 2014).

Although effective fungicides are available for preventing or reducing yield losses, use of fungicides adds a significant cost for wheat production and may have adverse effects for the environment (Chen 2014; Line 2002). In 2010, although millions of dollars were spent on fungicide applications to reduce the severity of stripe rust epidemics, yield loss was still estimated at 2.6 million metric tons in the United States (Chen 2014). Control of stripe rust has often been achieved through developing and growing resistant cultivars, which is considered to be the most effective, easy-to-use, economical, and environmentally friendly approach (Chen 2013; Singh et al. 2013). Improving resistance to stripe rust is always a high priority in many regions of the world where stripe rust epidemics occur frequently.

Two different types of resistance have been used in breeding programs (Chen 2005, 2013; Line 2002; Line and Chen 1995). All-stage resistance provides high-level resistance throughout the plant growth stages, but does not last long due to its race specificity and the emergence of corresponding virulent races. In contrast, high-temperature adult-plant (HTAP) resistance, which expresses when weather become warm and plants grow old, is generally nonrace specific and durable (Chen 2013; Line 2002; Qayoum and Line 1985). However, HTAP resistance may not be adequate for protecting crops from significant damage as individual genes conferring this type of resistance usually provide only partial resistance, and its expression is influenced by plant growth stage, temperatures, and disease pressure (Chen 2005, 2013, 2014). Although high-level HTAP resistance can be achieved by combining different genes for this type resistance, the seedling susceptibility in cultivars with only HTAP resistance allows infection by the pathogen and building up the disease pressure in the early crop season, resulting in significant damage (Chen 2005, 2014). Pyramiding two or more genes for effective race-specific allstage resistance genes into individual cultivars may make resistance 
last longer (Bariana et al. 2007; Chemayek et al. 2017; Chen 2013). It is even better to combine effective all-stage resistance and HTAP resistance because this approach takes the advantages and overcomes the disadvantages of both types of resistance (Chen 2013).

Pyramiding multiple genes for disease resistance has been reported in barley, cotton, pea, rice, soybean, wheat, and other crops (Chen 2013; Chemayek et al. 2017; Cox et al. 1994; Gahan et al. 2005; Jackson et al. 2003; Schneider 2002; Shi et al. 2009; Werner et al. 2005; Yasuda et al. 2015). Several wheat cultivars, such as Clearwhite 515, Expresso, Patwin 515, Scarlet 09, Summit 515, and Seahawk grown in the western United States, were developed by pyramiding stripe rust resistance genes $\mathrm{Yr} 15$ with $\mathrm{Yr} 5$ or $\mathrm{Yr} 17$. However, in these cultivars, genes for pyramiding were from different chromosomes. Genes on different chromosomes pyramided in a particular cultivar will segregate in new crosses, and some of the genes may be lost during the breeding process. An example of lost genes is the development of imidazolinone (IMI)-resistant wheat cultivar ORCL-102 from 'Madsen' (http://www.otseeds.com/products/ orcf102.pdf). Madsen has five stripe rust resistance quantitative trait loci (QTLs) on different chromosomes, whereas ORCL-102 does not have the major QTL on chromosome 2AS (Liu et al. 2018). The high-

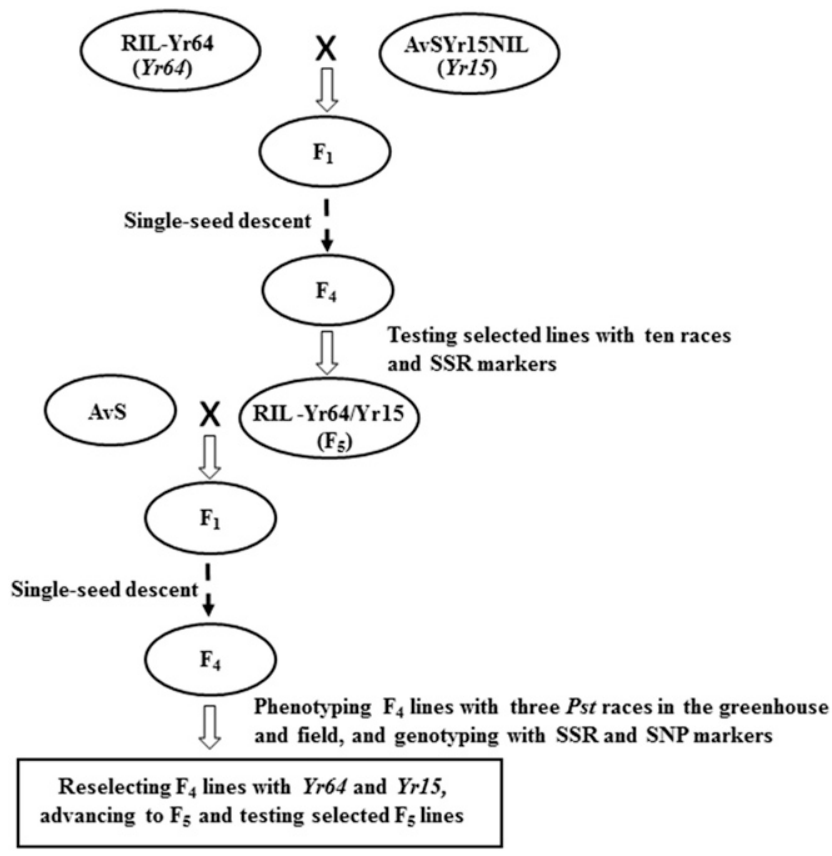

Fig. 1. The scheme of pyramiding and validating stripe rust resistance genes $\mathrm{Yr} 64$ and Yr15 linked in the short arm of chromosome 1B in wheat lines. level, durable resistance has protected Madsen from significant yield losses, whereas ORCL-102 has suffered significant yield losses since their releases in 1988 and 2004, respectively (Chen 2014; Liu et al. 2018). Pyramiding genes linked in repulsion from different genotypes may keep them together into new cultivars. This approach may provide long lasting resistance, increase the level of resistance, and accelerate the pyramiding and selection processes in breeding programs. Chemayek et al. (2017) proposed to combine stem rust resistance genes $\mathrm{Sr} 36$ and $\mathrm{Sr} 39$, both located on wheat chromosome 2B originally from T. timopheevii and Aegilops speltoides, respectively. However, no wheat cultivars have been reported to carry both genes. For stripe rust, no studies have reported pyramiding genes linked in repulsion.

Wild relatives of wheat are important sources of genes for resistance to diseases including stripe rust. Several stripe rust resistance genes have been discovered from tetraploid wheat species including wild emmer wheat (T. turgidum L. subsp. dicoccoides [Korn. ex Asch. \& Graebn.] Thell.) and durum wheat (T. turgidum L. subsp. durum [Desf.] Husn., $2 \mathrm{n}=4 \mathrm{x}=28$, AABB genomes). Two stripe rust resistance genes, $\mathrm{Yr} 15$ and $\mathrm{YrH}$ 52, were originally identified from wild emmer wheat and have been transgressed into hexaploid common wheat using a chromosome 1BS translocation line (GerechterAmitai et al. 1989; Mandoulakani et al. 2015; Peng et al. 2000). Thanks to the near-isogenic line developed for Yr15 (Wellings et al. 2009) and its high resistance to most Pst races over the world, the gene has been widely used in wheat breeding programs for developing wheat cultivars with resistance to stripe rust (Wang and Chen 2017). So far, $\operatorname{Yr} 15$ is effective against all Pst races identified in the United States (Liu et al. 2017; Wan and Chen 2014; Wan et al. 2016), making it an excellent gene to be pyramided with other genes for developing highly durable, resistant wheat cultivars.

Similar to $\operatorname{Yr} 15, \operatorname{Yr} 64$ was transgressed from durum wheat accession PI 331260 into a common spring wheat line and mapped to the short arm of chromosome 1B (Cheng et al. 2014). Yr64 is also resistant to all tested $P s t$ races. Based on the common SSR markers in the linkage maps of Yr64 (Cheng et al. 2014) and Yr15 (Peng et al. 2000), the two genes were estimated to be linked in repulsion and separated by $7.8 \mathrm{cM}$ (Cheng et al. 2014). Since both $Y r 64$ and $Y r 15$ provide resistance to a broad spectrum of races and are located closely on chromosome 1BS, the objectives of this study were to i) develop a wheat line with both Yr64 and Yr15 and ii) validate the combination of the two genes by phenotyping and genotyping a mapping population developed from a test cross of the line with the two genes to a susceptible line. New lines were selected from the progenies of the test cross based on their highly resistant reaction and molecular genotypes. These lines and molecular markers will be useful for incorporating the double-gene resistance into new wheat cultivars with highly durable resistance to stripe rust.

\section{Materials and Methods}

Developing a common wheat line presumably possessing Yr64 and Yr15. The schematic procedure for crossing, backcrossing,

Table 1. Infection types of AvS, PI 331260 (Yr64), RIL-Yr64 (Yr64), AvSYr15NIL (Yr15) and RIL-Yr64/Yr15 (Yr64 and Yr15) to 10 races of Puccinia striiformis f. sp. tritici (Pst) tested under controlled greenhouse conditions

\begin{tabular}{|c|c|c|c|c|c|c|c|}
\hline \multirow[b]{2}{*}{ Pst race } & \multirow[b]{2}{*}{ Isolate } & \multirow[b]{2}{*}{ Virulence formula ( $\mathrm{Yr}$ genes $)^{\mathrm{a}}$} & \multicolumn{5}{|c|}{ Infection type } \\
\hline & & & AvS & PI 331260 & RIL-Yr64 & AvSYr15NIL & RIL-Yr64/Yr15 \\
\hline 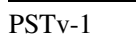 & $2010-375$ & 1 & 9 & 0 & 1 & 0 & 0 \\
\hline PSTv-59 & 1982-015-10 & $6,17, \operatorname{Tr} 1,76$ & 9 & 1 & 1 & 0 & 0 \\
\hline PSTv-172 & 1985-006 & $6,10,24,44, \operatorname{Tr} 1$ & 9 & 1 & 1 & 0 & 0 \\
\hline PSTv-28 & 2000-180-16 & 6,7,9,17,44,Ехр2 & 9 & 1 & 1 & 0 & 0 \\
\hline PSTv-30 & 2000-041 & $6,7,8,9,44, \operatorname{Tr} 1, \operatorname{Exp} 2$ & 9 & 1 & 1 & 1 & 0 \\
\hline PSTv-37 & $2003-42$ & $6,7,8,9,17,27,43,44, \operatorname{Tr} 1, \operatorname{Exp} 2$ & 9 & 1 & 1 & 1 & 0 \\
\hline PSTv-11 & $2008-316$ & $1,6,7,8,9,17,27,43,44, \operatorname{Exp} 2,76$ & 9 & 2 & 2 & 1 & 0 \\
\hline PSTv-14 & $2012-116$ & $1,6,7,8,9,17,27,43,44, \operatorname{Tr} 1, \operatorname{Exp} 2,76$ & 9 & 2 & 2 & 1 & 0 \\
\hline PSTv-40 & $2007-172$ & $6,7,8,9,10,24,27,32,43,44, \operatorname{Tr} 1, \operatorname{Exp} 2$ & 9 & 1 & 1 & 1 & 0 \\
\hline PSTv-51 & 2011-366 & $1,6,7,8,9,10,17,24,27,32,43,44, \mathrm{SP}, \operatorname{Tr} 1, \operatorname{Exp} 2,76$ & 9 & 2 & 2 & 1 & 0 \\
\hline
\end{tabular}

${ }^{a}$ The virulence formulae were based on the $18 \mathrm{Yr}$ single-gene differentials: $Y r 1, Y r 5, Y r 6, Y r 7, Y r 8, Y r 9, Y r 10, Y r 15, Y r 17, Y r 24, Y r 27, Y r 32, Y r 43, Y r 44, Y r S P$,

YrTr1, YrExp2, Yr76 (YrTye) (Liu et al. 2017; Wan and Chen 2014; Wan et al. 2016). 
selection, and mapping is illustrated in Figure 1. To combine Yr64 and $Y$ r 15, a cross was made between a recombinant inbred line (RIL), RIL-Yr64 carrying Yr64 and a near-isogenic line (NIL) in the Avocet S (AvS) background, AvSYr15NIL carrying Yr15 using the former as the female parent in a greenhouse. RIL-Yr64 is a common spring wheat line (T. aestivum) selected from the $\mathrm{F}_{7}$ population derived from a cross between common spring wheat 'Avocet $S$ ' (AvS) and durum wheat PI 331260 (T. turgidum ssp. durum) (Cheng et al. 2014). AvSYr15NIL is also a common spring wheat line developed by Wellings et al. (2009) through backcrossing six times. $F_{1}$

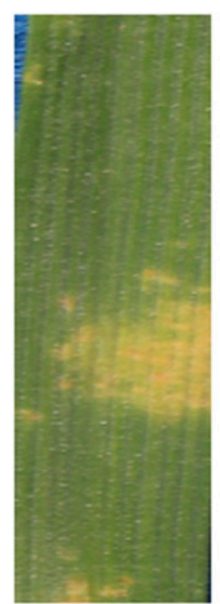

RIL-Yr64

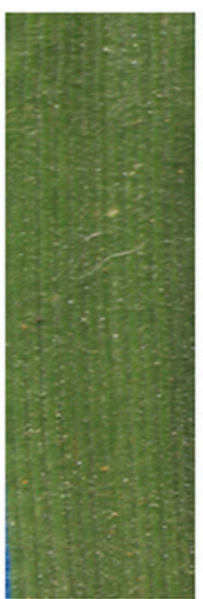

AvSYr15NIL

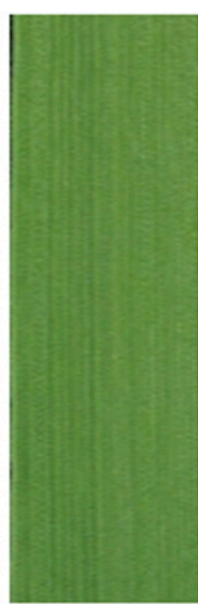

RIL-Yr64/Yr15

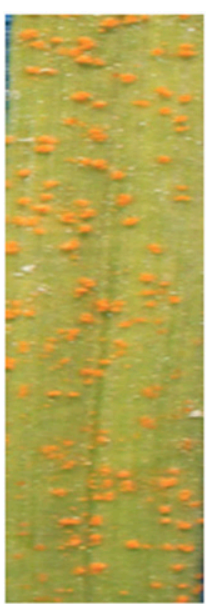

AvS
Fig. 2. Seedling reactions of wheat lines RIL-Yr64, AvSYr15NIL, RIL-Yr64/Yr15, and Avocet S (AvS) to race PSTv-11 of Puccinia striiformis $\mathrm{f}$. $\mathrm{sp}$. tritici in the greenhouse. RIL-Yr64 was selected from progeny of AvS $\times$ PI 331260 (Cheng et al. 2014); AvSYr15NIL was a near-isogenic line for Yr15 in the AvS background (Wellings et al. 2009); and RIL-Yr64/Yr15 was a $F_{4}$ line selected from cross RIL-Yr64 $\times$ AvSYr15NIL presumably carrying both Yr64 and Yr15 on the short arm of chromosome 1B.

A
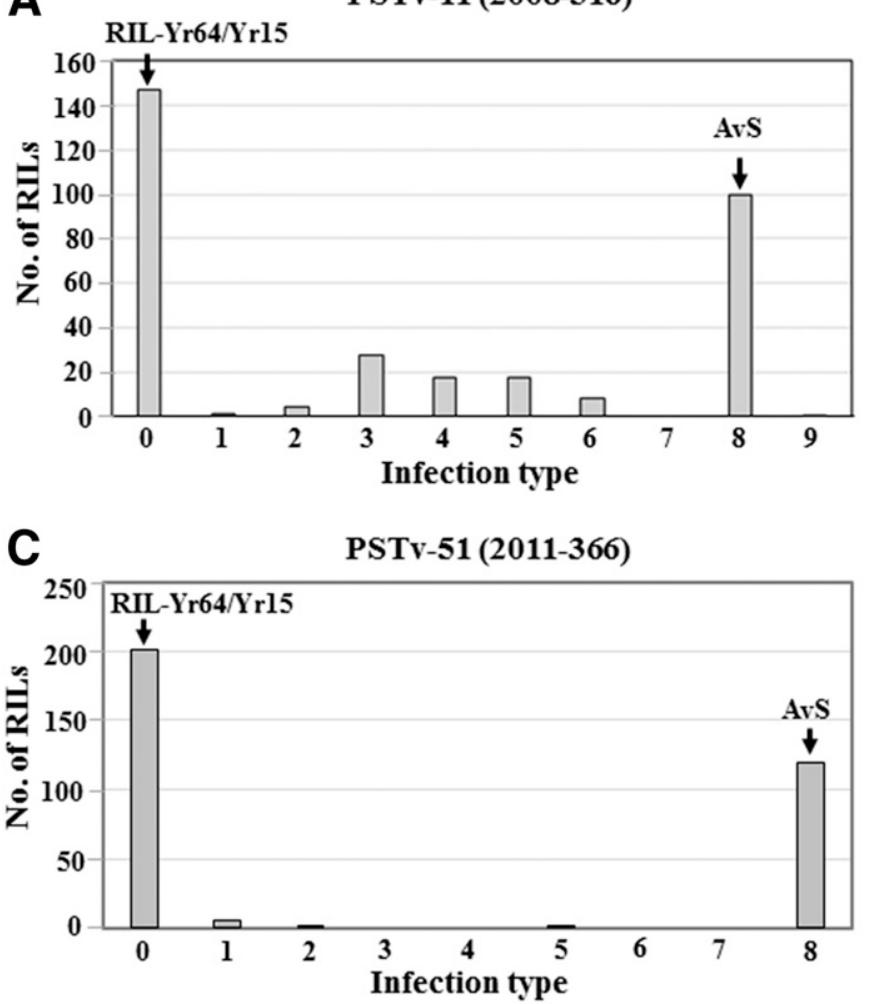

plants from the RIL-Yr64 $\times$ AvSYr15NIL cross were grown in the greenhouse to produce $F_{2}$ seeds. Similarly, $F_{3}$ and $F_{4}$ seeds were produced in the greenhouse and $\mathrm{F}_{5}$ seeds in the field using the single seed descent (SSD) method. Seedlings of each generation were tested with race PSTV-11 (previously PST-127 using wheat cultivar differentials) in the greenhouse. Progenies selected based on the phenotype (either IT 0 or IT 8-9) were advanced. A population of more than $1,000 \mathrm{~F}_{2}$ plants were selected and advanced to $90 \mathrm{~F}_{4}$ lines. The $\mathrm{F}_{4}$ lines were evaluated in a field near Pullman, WA, under natural Pst infection in 2014, together with AvS, PI 331260, RIL-Yr64, and AvSYr15NIL. One line was selected from the $\mathrm{F}_{4}$ progenies based on its homozygous infection type (IT $=0)$ in the field. This line was also tested together with AvS, PI 331260, RIL-Yr64, and AvSYr15NIL in the seedling stage in the greenhouse with 10 Pst races (Table 1) and using SSR marker Xgwm413 for Yr64 (Cheng et al. 2014) and markers Xbarc8 and Xgwm273 for $\operatorname{Yr} 15$ (Murphy et al. 2009). This line was presumed to have both Yr64 and Yr15, and therefore, designated as RIL-Yr64/Yr15 and crossed to AvS to develop a mapping population.

Developing a mapping population from AvS × RIL-Yr64/ Yr15. RIL-Yr64/Yr15 was crossed to AvS, and $F_{1}$ plants were grown in the greenhouse. Seedlings of $327 \mathrm{~F}_{2}$ plants derived from a single $F_{1}$ plant were evaluated in the greenhouse for stripe rust reactions and the seedlings were transferred to bigger pots $(10 \times 10 \times 10 \mathrm{~cm})$ after scoring and removing sporulating leaves to produce $\mathrm{F}_{3}$ seed. The $\mathrm{F}_{3}$ lines were planted in a field near Pullman, WA, in 2015 to produce $\mathrm{F}_{4}$ seeds. The $327 \mathrm{~F}_{4}$ lines were used for stripe rust phenotyping and marker genotyping.

Evaluating wheat plants/lines for stripe rust reaction. The stripe rust reactions of PI 331260, RIL-Yr64, AvSYr15NIL, RILYr64/Yr15, and AvS were tested with 10 races (Table 1) in the seedling stage under controlled conditions following the standard procedures (Chen and Line 1992). Briefly, seeds were sown in a plastic tray $(27.5 \mathrm{~W} \times 53.43 \mathrm{~L} \times 6.10 \mathrm{D} \mathrm{cm})$ containing 72 cells (one seed per cell for $F_{2}$ and 10 to 15 seeds per cell for individual lines) filled with soil mixture. About 10 days after planting, seedlings at the two-
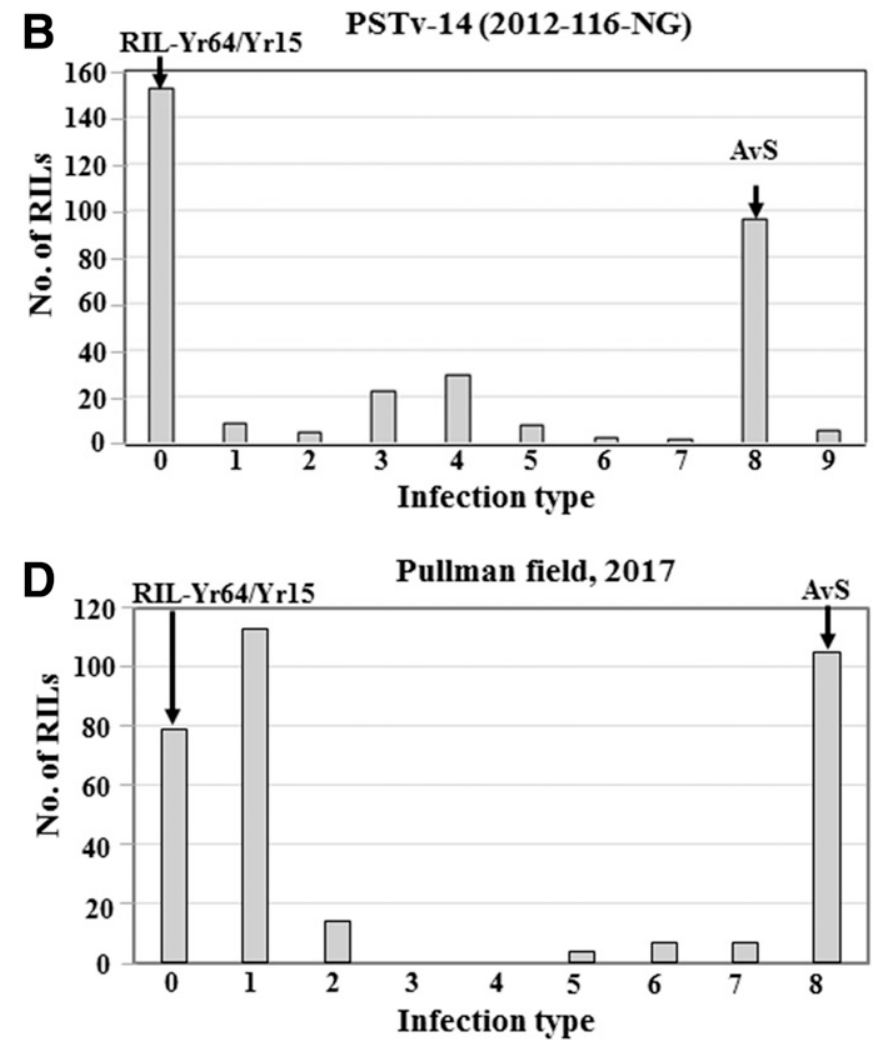

Fig. 3. The distribution of infection types among $327 \mathrm{~F}_{4}$ RILs derived from the cross of AvS $\times$ RIL-Yr64/Yr15 tested with races PSTv-11 (isolate $\left.2008-316\right)$ (A), PSTV-14 (isolate 2012-116-NG) (B), PSTv-51 (2011-366) (C), and in the field near Pullman in 2017 (D). 
leaf stage were dust-inoculated with urediniospores mixed with talc at the ratio of 1:20. The inoculated seedlings were kept in a dew chamber at $10^{\circ} \mathrm{C}$ in dark for $24 \mathrm{~h}$, and then transferred to a growth chamber at the diurnal temperature gradually changing from $4{ }^{\circ} \mathrm{C}$ at 2:00 A.M. to $20^{\circ} \mathrm{C}$ at 2:00 P.M. with a $16 \mathrm{~h}$ light $/ 8 \mathrm{~h}$ dark photoperiod. Stripe rust infection type (IT) of each plant or each line was scored at 18 to 21 days after inoculation using the 0 to 9 scale (Line and Qayoum 1992) with IT 0 for no visible signs or symptom, IT 1 for only tiny necrotic or chlorotic flecks, IT 2 for necrotic or chlorotic blotches (or stripes for adult plants) without any sporulation, IT 3 for necrotic or chlorotic blotches (or stripes) with trace sporulation, IT 4 for necrotic or chlorotic blotches (stripes) with light sporulation, IT 5 for necrotic or chlorotic blotches (stripes) with intermediate sporulation, IT 6 for necrotic or chlorotic blotches (stripes) with moderate sporulation, IT 7 for abundant sporulation with necrotic or chlorotic blotches (stripes), IT 8 for abundant sporulation with chlorosis, and IT 9 for abundant sporulation without necrosis or chlorosis.

For generation advancing and stripe rust evaluation in the field, about 30 seeds per line were planted in a row of $40 \mathrm{~cm}$ long with a $20 \mathrm{~cm}$ space between rows in April in either only Pullman or both Pullman and Mount Vernon, WA. The IT data from natural Pst infection were recorded in the flowering or milk stage when AvS had more than $90 \%$ rust severity, and the data were used to select lines for advancement and/or further testing. The selected $\mathrm{F}_{4}$ lines from the RIL-

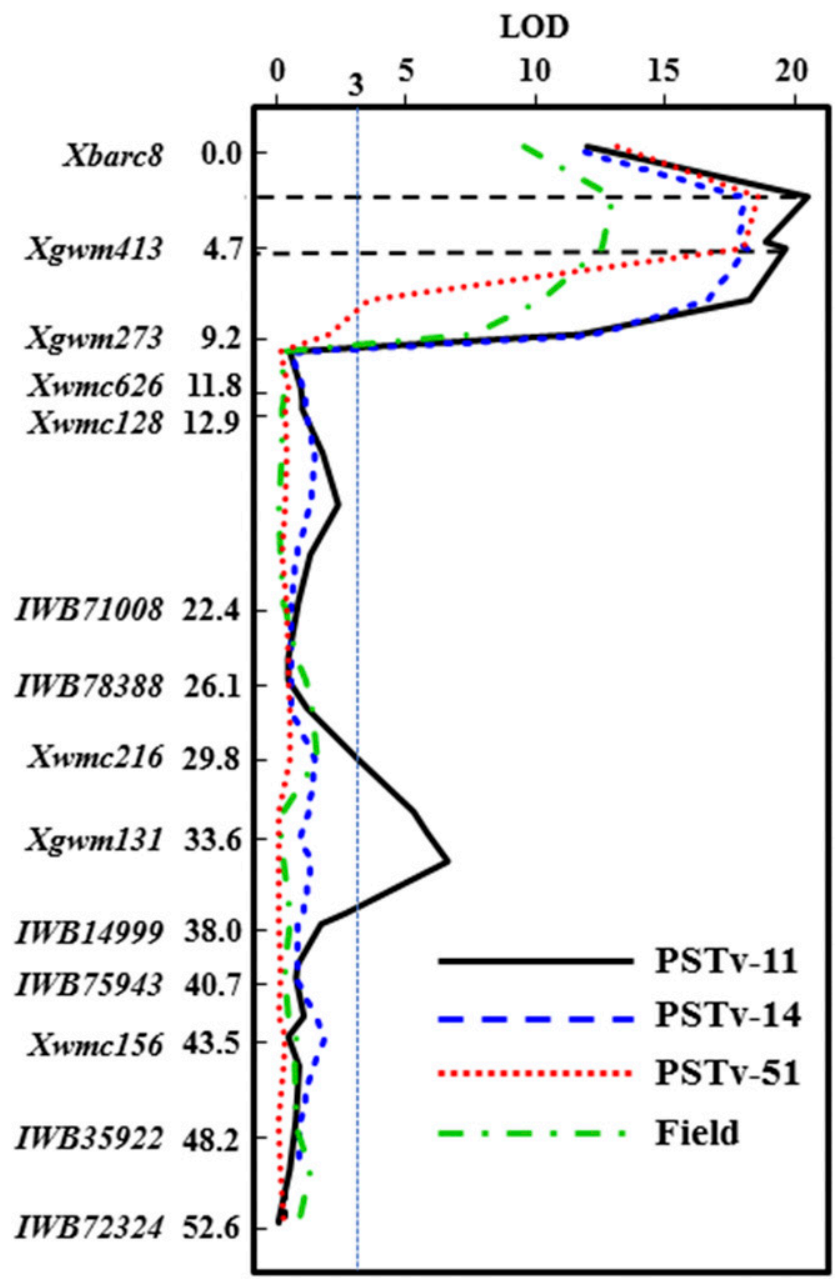

Fig. 4. Mapping of QTLs for stripe rust resistance along chromosome $1 \mathrm{~B}$ using greenhouse seedling tests with race PSTv-11 (isolate 2008-316), PSTv-14 (2012116-NG), PSTv-51 (2011-366), and under natural infection of Puccinia striiformis f. sp. tritici at the adult-plant stage in Pullman during the 2017 growth season. The vertical dash line indicates the LOD threshold of 3.0 determined by permutation test with 1,000 cycles and the horizontal dashed lines indicates two loci mapped using resistant (IT 0-2), segregating (IT 0-8), and susceptible (IT 7-9).
Yr64 $\times$ AvSYr15NIL cross were evaluated in both Pullman and Mount Vernon in 2014.

$\mathrm{F}_{2}$ seedlings from the AvS $\times$ RIL-Yr64/Yr15 cross were evaluated with PSTv-11 (PST-127), one of the most virulent races detected using the old set of wheat cultivar differentials (Chen et al. 2010) in the greenhouse in 2015. The $\mathrm{F}_{4}$ lines from the same cross were evaluated with three races, PSTv-11 (isolate 2008-316), PSTv-14 (isolate 2012-116-NG), and PSTv-51 (2011-366) in the greenhouse in 2016-2017 (Table 1). The last one is the most virulent race identified so far using the $18 \mathrm{Yr}$ single-gene line differentials (Wan and Chen 2014; Wan et al. 2016). In 2017, the $F_{4}$ RILs were evaluated in the Pullman field using a randomized complete block design with three replications.

Genotyping wheat lines by SSR, SNP, and KASP markers. Plant genomic DNA was isolated from leaf tissues of the parental lines (AvS, RIL-Yr64, AvSYr15NIL, and RIL-Yr64/Yr15), the selected $\mathrm{F}_{4}$ lines of RIL-Yr64 $\times$ AvSYr15NIL, and $\mathrm{F}_{4}$ lines of AvS $\times$ RIL-Yr64/Yr15 using the CTAB method (Riede and Anderson 1996). To reduce the problem of segregating plants, one plant for each $\mathrm{F}_{4}$ line was used to extract DNA. DNA concentration was measured using a NanoDrop ND-1000 (Thermo Scientific, Wilmington, DE) and the DNA quality was determined by $0.8 \%$ agarose gel electrophoresis. The DNA concentration was adjusted to $25 \mathrm{ng} / \mu \mathrm{l}$ for genotyping using SSR markers. The flanking SSR markers from Cheng et al. (2014) were used to genotype the selected progeny lines from RIL-Yr64 × AvSYr15NIL. To map the genes and dissect chromosome $1 \mathrm{~B}$ in the $\mathrm{F}_{4}$ populations resulting from the AvS $\times$ RILYr64/Yr15 cross, 26 SSR markers along chromosome 1B (Supplementary Table S1), including the markers in the linkage maps of Yr64 and Yr15 (Cheng et al. 2014; Mandoulakani et al. 2015; Murphy et al. 2009) were tested on AvS, RIL-Yr64, AvSYr15NIL, and RIL-Yr64/Yr15. Based on the results, eight SSR markers that were polymorphic between AvS and RIL-Yr64/Yr15 were used to genotype the $\mathrm{F}_{4}$ lines. Polymerase chain reactions (PCR) using SSR markers were performed in an Applied Biosystems 2720 thermal cycler with a total of $12 \mu \mathrm{l}$ reaction mixture containing $50 \mathrm{ng}$ DNA template, $1.0 \mathrm{U}$ Taq DNA polymerase, $1.2 \mu \mathrm{l} 10 \times \mathrm{PCR}$ buffer $(50 \mathrm{mM}$ of $\mathrm{KCl}, 10 \mathrm{mM}$ of Tris-HCl, $\mathrm{pH}$ 8.3), $2.4 \mathrm{mM}$ dNTP mixture, $12 \mathrm{mM}$ $\mathrm{MgCl}_{2}, 0.6 \mu \mathrm{M}$ of forward primer, $3.0 \mu \mathrm{M}$ reverse primer, and $2.4 \mathrm{mM}$ M13 primer. The PCR reaction was performed at $94.0^{\circ} \mathrm{C}$ for $5 \mathrm{~min}, 35$ to 45 cycles of $\left(94.0^{\circ} \mathrm{C}\right.$ for $30 \mathrm{~s}, 50,55$, or $60^{\circ} \mathrm{C}$ (according to each primer pair) for $30 \mathrm{~s}, 72^{\circ} \mathrm{C}$ for $1 \mathrm{~min}$, and the final extension at $72^{\circ} \mathrm{C}$ for $7 \mathrm{~min}$. After PCR amplification, denaturing was performed following the procedure described by Hou et al. (2015). The denatured PCR products were analyzed using capillary electrophoresis on an ABI3730xl DNA analyzer (Applied Biosystems, Foster City, CA). The allele for each sample was called using Gene Marker version 2.2.0 software (http://genemarker.software.informer.com/2.2/).

To identify more polymorphic markers for constructing a highresolution map for the chromosomal regions containing Yr64 and Yr15, AvS and RIL-Yr64/Yr15 were genotyped using the 90K SNP iSelect assay (Wang et al. 2014). From 72 SNP markers polymorphic between the two parental lines on chromosome 1B, 29 SNPs spanning between the positions of 3 and $109 \mathrm{cM}$ were selected for converting to Komptitive allele-specific PCR (KASP) markers using the information provided by PolyMarker (http://polymarker.tgac.ac. uk/). The KASP markers were synthesized by Sigma-Aldrich Inc. (St. Louis, MO). The 29 KASP markers (Supplementary Table S2) were screened on the parental lines AvS, RIL-Yr64/Yr15, RILYr64, and AvSYr15NIL. Six markers, which were polymorphic between AvS and RIL-Yr64/Yr15, were used to genotype the $F_{4}$ population of AvS $\times$ RIL-Yr64/Yr15. The PCR reactions using KASP markers were conducted in an Applied Biosystems 2720 Thermal Cycler following the manufacturer's instructions (https://www. lgcgroup.com/products/kasp-genotyping-chemistry/kasp-technicalresources/\#.WnuRPKinGUk). A KASP primer solution was prepared by mixing $1.2 \mu \mathrm{mol}$ forward primer $\mathrm{A}, 1.2 \mu \mathrm{mol}$ forward primer B, and $3.0 \mu \mathrm{mol}$ reverse primer C. A volume of $15 \mu \mathrm{l} \mathrm{PCR}$ solution contained $7.5 \mu$ KASP master mix, $0.21 \mu$ KASP primer 
solution, and $100 \mathrm{ng}$ DNA template. The reactions started at $94.0^{\circ} \mathrm{C}$ for $15 \mathrm{~min}, 10$ cycles of $94.0^{\circ} \mathrm{C}$ for $20 \mathrm{~s}$ and $65.0^{\circ} \mathrm{C}$ with a decrease of $0.6^{\circ} \mathrm{C}$ per cycle for $1 \mathrm{~min}$, followed by 26 cycles of $94.0^{\circ} \mathrm{C}$ for $20 \mathrm{~s}$ and $57.0^{\circ} \mathrm{C}$ for $1 \mathrm{~min}$. The allele specificity was determined by a LightCycler 480 System using the Endpoint Genotyping software.

Constructing genetic linkage maps and QTL analysis. A genetic map was constructed using software JoinMap 4.1 (https://www. kyazma.nl/). QTL analysis was conducted using the composite interval mapping (CIM) model in the R/qtl software package (https:// www.rstudio.com/). A logarithm of odds (LOD) threshold value was determined by permutation test at 1,000 iterations. The graphic genetic maps of the parental lines were constructed using MapChart software (Voorrips 2002).

\section{Results}

Development of a common wheat line presumably possessing both Yr64 and Yr15. A common spring wheat line was selected from $\mathrm{F}_{4}$ lines derived from cross RIL-Yr64 $\times$ AvSYr15NIL. The selection of this line was started with an $\mathrm{F}_{2}$ plant that had IT 0 in the test with PSTv-11 (Fig. 2). The single-seed descent $F_{3}$ and $F_{4}$ lines from the $F_{2}$ plant showed uniform IT 0 , in comparison with different ITs and segregations in some other $\mathrm{F}_{2}$ plants and $\mathrm{F}_{3}$ or $\mathrm{F}_{4}$ lines (data not shown), confirming the homozygosity of IT 0 of the selected $\mathrm{F}_{2}$ plant to the most virulent race. The $F_{2}$ plant was advanced to an $F_{4}$ line together with other $F_{2}$ plants and derived $F_{3}$ lines, and its $F_{3}$ and $F_{4}$ lines were consecutively selected based on the stripe rust reactions of $F_{3}$ and $F_{4}$ lines in the greenhouse tests and the $\mathrm{F}_{4}$ test in the fields together with $\mathrm{F}_{4}$ marker-assisted selection (MAS). The resistance allele of the $\mathrm{Yr} 64$ locus was detected using SSR marker Xgwm413 and that of the $\mathrm{Yr} 15$ locus was detected using SSR markers Xbarc8 and Xgwm273 in the selected $\mathrm{F}_{4}$ line. The marker data indicated that the selected $\mathrm{F}_{4}$ line has both $\operatorname{Yr64}$ and $\mathrm{Yr} 15$, and therefore, it was temporarily named RIL-Yr64/Yr15.
To determine the broadness of the RIL-Yr64/Yr15 resistance, it was tested together with PI 331260, RIL-Yr64, AvSYr15NIL, and AvS with 10 Pst races (Table 1), which were selected based on their spectra of virulence genes and/or predominance. As expected, RILYr64/Yr15 was resistant to all 10 races, similar to PI 331260, RILYr64, and AvSYr15NIL, but showing IT 0 to all of the races, more resistant than the IT 1 (AvSYr15NIL) and IT 2 (PI 331260 and RIL-Yr64) of the parents (Table 1, Fig. 2).

Stripe rust phenotyping of the $F_{4}$ RIL population derived from AvS $\times$ RIL-Yr64/Yr15. When the $327 \mathrm{~F}_{4}$ lines derived from the cross of AvS $\times$ RIL-Yr64/Yr15 were tested together with AvS and RIL-Yr64/Yr15 with race PSTv-11 in the seedling stage in the greenhouse, 146 had uniform IT 0,82 had either uniform or segregating IT $0-9$ (at average 1 to 6), and 99 had uniform IT 8. The IT data of the $F_{4}$ lines together with AvS and RIL-Yr64/Yr15 are provided in Supplementary Table S3, and the distributions of different reactions are shown in Figure 3. The segregation of the population did not fit the ratio of $37.5 \%$ (lines with highest resistance and homozygous): $25 \%$ (lines with lower resistance reactions and segregating): $37.5 \%$ (lines with highest susceptibility and homozygous) for a single locus ( $P=$ $0.01)$. The segregation also did not fit an expected ratio of $65.625 \%$ : 25\%:9.375\% for these categories based on the model of two independent loci $(P<0.0001)$. However, the observed numbers of the three phenotypic categories fit the ratio of $44.3 \%: 25 \%: 29.7 \%(P=0.98)$ expected for two loci with a $7.8 \mathrm{cM}$ genetic distance between $\mathrm{Yr} 15$ and Yr64 (Cheng et al. 2014). The seedling tests with races PSTv-14 and PSTv-51, as well as the adult-plant data in the field test, produced similar results. All these results indicated that RIL-Yr64/Yr15 had two genes linked in coupling for resistance to stripe rust.

Construction of a linkage map and QTL mapping. A linkage map was constructed with eight SSR markers and six SNP markers, spanning $52.6 \mathrm{cM}$ along chromosome $1 \mathrm{~B}$ (Fig. 4). The 14 markers fit the ratio of $43.75 \%: 12.5 \%: 43.75 \%$ for $\mathrm{AA}, \mathrm{AB}$, and $\mathrm{BB}$ alleles for an

AvS

RIL-Yr64

RIL-Yr64/Yr15

AvSYr15NIL

Consensus map

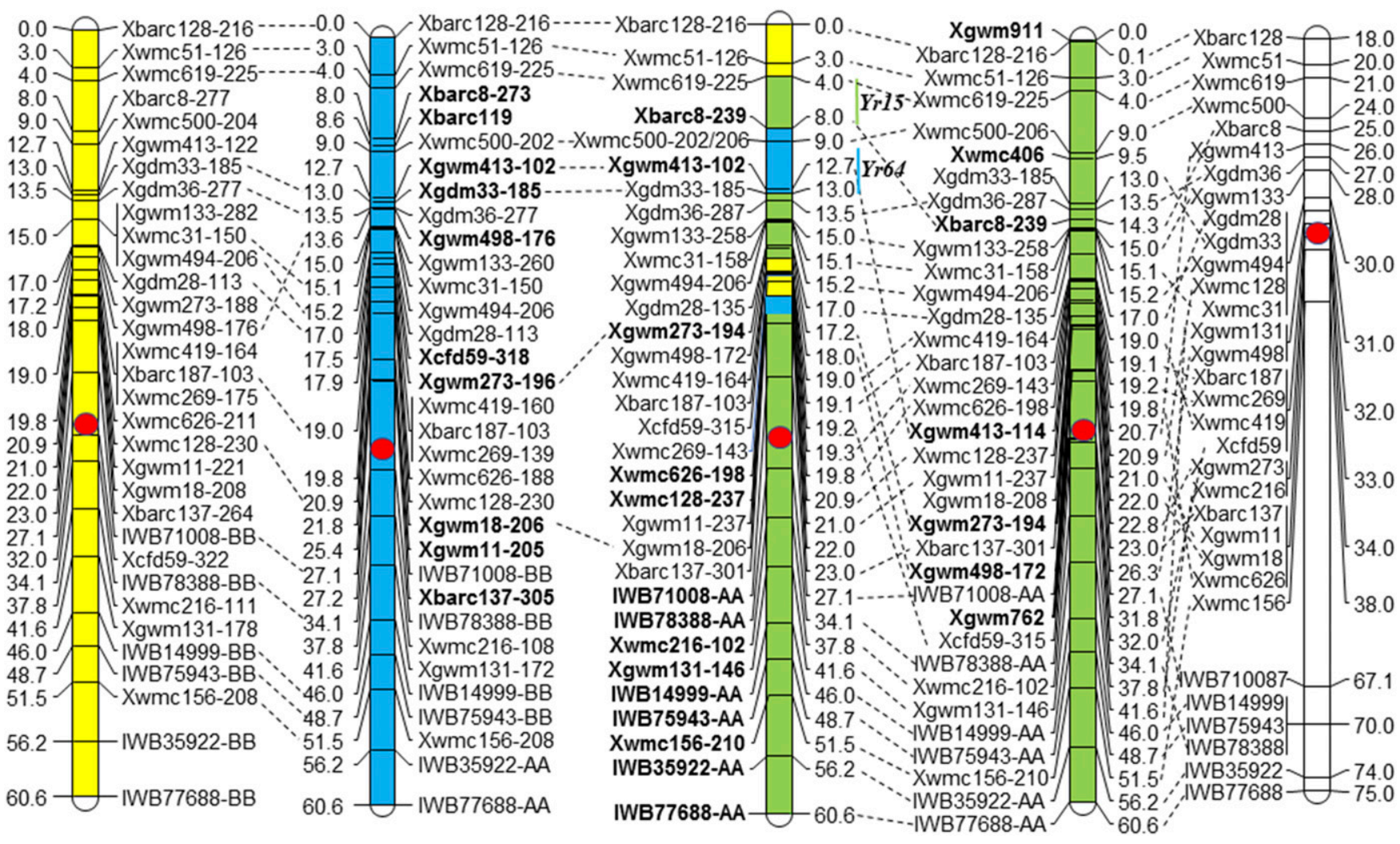

Fig. 5. The genetic map of chromosome 1B in RIL-Yr64/Yr15 in comparison with those of AvS, RIL-Yr64 (Cheng et al. 2014), AvSYr15NIL (Mandoulakani et al. (2015), and the consensus map (Somers et al. 2004; Wang et al. 2014). The markers in bold were in their maps and those not in bold were added based on the amplification in the present study referring their positions in the consensus map. The red dot in each linkage map shows the relative position of the centromere at about $32 \mathrm{cM}$ from the top of the short arm. 
$\mathrm{F}_{4}$ population. SSR markers Xbarc8 and Xgwm413 flanking the Yr15 locus (Murphy et al. 2009; Yaniv et al. 2015) were mapped to a $4.7 \mathrm{cM}$ interval; and Xgwm413 and Xgwm273 flanking Yr64 were mapped to a $4.5 \mathrm{cM}$ interval, similar to the results of Cheng et al. (2014).

The four phenotypical data mapped QTLs to the same region of $9.2 \mathrm{cM}$ between $X$ barc 8 and Xgwm273, and all the QTL peaks were greater than the LOD value of 12.0 (Fig. 4). The QTL region mapped based on the PSTv-11 seedling data had two peaks corresponding to the two loci of $\mathrm{Yr} 15$ and $\mathrm{Yr} 64$ in the previous study (Cheng et al. 2014; Mandoulakani et al. 2015) obtained by qualitative analysis. This result indicated that RIL-Yr64/Yr15 carried both Yr64 and Yr15. In addition, the PSTv-11 data also mapped a minor QTL (LOD $=6.2$ ) between SNP markers IWB78388 and IWB14999 (Fig. 4). This QTL was not detected by the other sets of IT data.

Dissection of chromosome 1B in RIL-Yr64/Yr15. To dissect chromosome 1B of RIL-Yr64/Yr15 for chromosomal parts introgressed from RIL-64, AvSYr15NIL, and AvS, the molecular markers that were tested on the four wheat lines, but not segregated between AvS and RIL-Yr64/Yr15, were incorporated into the linkage map with the segregated markers based on their linkage in the consensus map (Somers et al. 2004). The new linkage map of RIL-Yr64/Yr15 and the linkage maps of AvS, RIL-Yr64, AvSYr15NIL, and the consensus 1B are presented in Figure 5. The chromosomal region of 4 cM from Xbarc128 to Xwmc51 and around Xwmc619 close to the telomeric region was most likely from AvS as these three markers were identical among the four wheat lines and AvS was commonly used to develop the other three lines. RIL-Yr64/Yr15 had the same $225 \mathrm{bp}$ allele of $X b a r c 8$ as AvSYr15NIL, and thus, the $4 \mathrm{cM}$ chromosomal segment between Xwmc619 and Xbarc8 containing the $\mathrm{Yr} 15$ locus should have been transferred from AvSYr15NIL. The Xwmc500 locus in RIL-Yr64/Yr15 was heterozygous with an allele of 202 bp from RIL-Yr64 and an allele of 206 bp from
AvSYr15NIL. The homozygous 102 bp allele of Xgwm413 in RIL-Yr64/Yr15 was clearly from RIL-Yr64, which corresponded to the chromosomal segment containing $\operatorname{Yr} 64$. There was an additional short segment from AvS and an additional short segment from RIL-Yr64 proximal to the centromere from the stripe rust resistance gene region. The remaining chromosomal segments of the short arm and the entire long arm of chromosome 1B were apparently from AvSYr15NIL. As these segments were different from AvS, they should come from either the hexaploid wheat background or the wild emmer donor line of $\operatorname{Yr} 15$.

Selection of new $F_{5}$ lines from AvS $\times$ RIL-Yr64/Yr15. Fifteen $\mathrm{F}_{5}$ lines from AvS $\times$ RIL-Yr64/Yr15 were selected based on the IT data in the greenhouse seedling tests with all three races (PSTv-11, PSTV-14, and PSTv-51) and the 2017 field test under natural infection. The selections were based on the following criteria: 1) Lines must have IT 0 in all four phenotyping tests; 2) lines must have the alleles from the resistant parent, RIL-Yr64/Yr15 at the three markers (Xbarc8, Xgwm413, and Xgwm273) that cover the region of $Y r 15$ and Yr64 (Figs. 4 and 5); 3) all marker loci should be homozygous; 4) only one line was selected for each marker genotype. As the phenotyping tests were conducted using multiple plants and the genotyping tests were conducted using DNA from a single plant for each $\mathrm{F}_{4}$ line, the selected $\mathrm{F}_{5}$ lines were confirmed by testing with the three races and the molecular markers. In addition to the 14 markers used to construct the linkage map (Figs. 4 and 5), eight additional markers were used to genotype the selected $\mathrm{F}_{5}$ lines to determine the percentages of the 1B chromosome from RIL-Yr64/Yr15 and AvS (Table 2). Among the $15 \mathrm{~F}_{5}$ lines, the genotype of one line (AvS//Yr64/Yr15114) was the same as the resistant parent RIL-Yr64/Yr15, while the others had the proportions of the RIL-Yr64/Yr15 1B chromosome ranged from 33.3\% (AvS//Yr64/Yr15-114) to 95.2\% (AvS// Yr64/Yr15-14 and AvS//Yr64/Yr15-18), or had about 66.7-4.8\% of the AvS 1B chromosome. Maintaining $\operatorname{Yr} 64$ and $\operatorname{Yr} 15$ in various proportions of AvS or RIL-64/Yr15 may be useful for different

Table 2. Molecular genotypes and stripe rust reaction phenotypes of selected $\mathrm{F}_{5}$ lines derived from cross AvS $\times$ RIL-Yr64/Yr15 possessing $Y r 64$ and $\mathrm{Yr} 15$ on chromosome 1B

\begin{tabular}{|c|c|c|c|c|c|c|c|c|c|c|c|c|c|c|c|c|c|}
\hline \multirow[b]{2}{*}{ Marker } & \multicolumn{17}{|c|}{ Parents and $F_{5}$ lines of AvS $\times$ RIL-Yr64/Yr15 } \\
\hline & AvS & RIL-Yr64/Yr15 & 114 & 14 & 18 & 22 & 150 & 327 & 255 & 35 & 25 & 140 & 119 & 147 & 270 & 66 & 235 \\
\hline Xbarc8 & $\mathrm{BB}$ & AA & $\mathrm{AA}$ & AA & AA & AA & $\mathrm{AA}$ & AA & AA & AA & AA & AA & AA & AA & AA & AA & $\overline{\mathrm{AA}}$ \\
\hline Xgwm413 & BB & AA & AA & AA & AA & AA & $\mathrm{AA}$ & AA & AA & AA & $\mathrm{AA}$ & AA & AA & AA & AA & AA & AA \\
\hline Xgwm 273 & $\mathrm{BB}$ & AA & $\mathrm{AA}$ & $\mathrm{AA}$ & AA & $\mathrm{AA}$ & $\mathrm{AA}$ & AA & $\mathrm{AA}$ & AA & $\mathrm{AA}$ & $\mathrm{AA}$ & AA & AA & AA & $\mathrm{AA}$ & AA \\
\hline Xwmc626 & BB & AA & AA & AA & AA & AA & AA & AA & AA & AA & AA & AA & AA & AA & AA & AA & AA \\
\hline Xwmc128 & BB & AA & AA & AA & AA & $\mathrm{AA}$ & $\mathrm{AA}$ & AA & AA & AA & $\mathrm{BB}$ & AA & AA & AA & AA & $\mathrm{AA}$ & AA \\
\hline IWB71008 & $\mathrm{BB}$ & $\mathrm{AA}$ & AA & AA & AA & $\mathrm{AA}$ & $\mathrm{AA}$ & $\mathrm{AA}$ & $\mathrm{AA}$ & $\mathrm{AA}$ & $\mathrm{AA}$ & $\mathrm{AA}$ & AA & $\mathrm{AA}$ & $\mathrm{BB}$ & $\mathrm{BB}$ & BB \\
\hline IWB78388 & $\mathrm{BB}$ & $\mathrm{AA}$ & AA & $\mathrm{AA}$ & AA & AA & $\mathrm{AA}$ & $\mathrm{AA}$ & AA & $\mathrm{AA}$ & $\mathrm{AA}$ & $\mathrm{AA}$ & AA & AA & $\mathrm{BB}$ & $\mathrm{BB}$ & BB \\
\hline$X w m c 216$ & BB & AA & $\mathrm{AA}$ & AA & AA & $\mathrm{AA}$ & $\mathrm{AA}$ & $\mathrm{AA}$ & AA & $\mathrm{AA}$ & $\mathrm{AA}$ & $\mathrm{AA}$ & AA & AA & BB & $\mathrm{BB}$ & BB \\
\hline Xgwm131 & $\mathrm{BB}$ & $\mathrm{AA}$ & $\mathrm{AA}$ & AA & AA & $\mathrm{AA}$ & $\mathrm{AA}$ & $\mathrm{AA}$ & $\mathrm{AA}$ & $\mathrm{AA}$ & $\mathrm{AA}$ & $\mathrm{AA}$ & AA & $\mathrm{AA}$ & $\mathrm{BB}$ & $\mathrm{BB}$ & BB \\
\hline IWB14999 & $\mathrm{BB}$ & $\mathrm{AA}$ & $\mathrm{AA}$ & $\mathrm{AA}$ & AA & AA & $\mathrm{AA}$ & $\mathrm{AA}$ & AA & $\mathrm{AA}$ & $\mathrm{AA}$ & $\mathrm{AA}$ & AA & AA & $\mathrm{BB}$ & $\mathrm{BB}$ & BB \\
\hline IWB75943 & BB & AA & AA & AA & AA & $\mathrm{AA}$ & AA & AA & $\mathrm{AA}$ & AA & $\mathrm{AA}$ & $\mathrm{AA}$ & AA & AA & BB & $\mathrm{BB}$ & BB \\
\hline Xwmc156 & $\mathrm{BB}$ & $\mathrm{AA}$ & $\mathrm{AA}$ & AA & $\mathrm{AA}$ & $\mathrm{AA}$ & $\mathrm{AA}$ & AA & $\mathrm{AA}$ & $\mathrm{AA}$ & $\mathrm{AA}$ & $\mathrm{AA}$ & AA & $\mathrm{AA}$ & $\mathrm{BB}$ & $\mathrm{BB}$ & BB \\
\hline IWB35922 & $\mathrm{BB}$ & AA & AA & AA & AA & AA & $\mathrm{AA}$ & $\mathrm{BB}$ & AA & AA & AA & AA & AA & AA & $\mathrm{BB}$ & $\mathrm{BB}$ & BB \\
\hline IWB77688 & BB & AA & AA & AA & AA & AA & AA & $\mathrm{AA}$ & AA & AA & $\mathrm{AA}$ & $\mathrm{AA}$ & AA & BB & BB & BB & BB \\
\hline Xgwm274 & $\mathrm{BB}$ & AA & AA & AA & AA & $\mathrm{AA}$ & $\mathrm{AA}$ & $\mathrm{AA}$ & $\mathrm{BB}$ & AA & $\mathrm{AA}$ & $\mathrm{BB}$ & $\mathrm{BB}$ & $\mathrm{BB}$ & $\mathrm{BB}$ & $\mathrm{AA}$ & BB \\
\hline Xwmc416 & $\mathrm{BB}$ & AA & AA & $\mathrm{BB}$ & AA & $\mathrm{BB}$ & $\mathrm{AA}$ & $\mathrm{BB}$ & AA & $\mathrm{BB}$ & $\mathrm{AA}$ & AA & $\mathrm{BB}$ & $\mathrm{BB}$ & AA & $\mathrm{BB}$ & AA \\
\hline Xwmc156 & BB & AA & AA & AA & AA & $\mathrm{AA}$ & $\mathrm{AA}$ & $\mathrm{AA}$ & $\mathrm{AA}$ & $\mathrm{AA}$ & $\mathrm{AA}$ & AA & AA & AA & $\mathrm{BB}$ & $\mathrm{BB}$ & $\mathrm{BB}$ \\
\hline Xwmc216 & $\mathrm{BB}$ & AA & AA & AA & AA & $\mathrm{AA}$ & $\mathrm{AA}$ & $\mathrm{AA}$ & AA & $\mathrm{AA}$ & $\mathrm{AA}$ & $\mathrm{AA}$ & AA & AA & $\mathrm{BB}$ & $\mathrm{BB}$ & BB \\
\hline Xbarc188 & $\mathrm{BB}$ & AA & AA & AA & AA & $\mathrm{AA}$ & $\mathrm{BB}$ & AA & $\mathrm{BB}$ & $\mathrm{BB}$ & $\mathrm{BB}$ & $\mathrm{BB}$ & $\mathrm{BB}$ & $\mathrm{BB}$ & $\mathrm{AA}$ & AA & BB \\
\hline Xwmc206 & BB & AA & AA & AA & AA & AA & $\mathrm{BB}$ & AA & $\mathrm{BB}$ & $\mathrm{BB}$ & $\mathrm{BB}$ & $\mathrm{BB}$ & $\mathrm{BB}$ & $\mathrm{BB}$ & AA & $\mathrm{AA}$ & BB \\
\hline Xwmc367 & $\mathrm{BB}$ & AA & $\mathrm{AA}$ & AA & BB & $\mathrm{BB}$ & $\mathrm{BB}$ & $\mathrm{BB}$ & AA & BB & $\mathrm{BB}$ & $\mathrm{BB}$ & BB & $\mathrm{BB}$ & $\mathrm{AA}$ & $\mathrm{BB}$ & $\mathrm{AA}$ \\
\hline No. of loci from AvS & 0 & 0 & 0 & 1 & 1 & 2 & 3 & 3 & 3 & 4 & 4 & 4 & 5 & 6 & 12 & 13 & 14 \\
\hline Percentage of AvS 1B (\%) & 100 & 0.0 & 0.0 & 4.8 & 4.8 & 9.5 & 14.3 & 14.3 & 14.3 & 19.0 & 19.0 & 19.0 & 23.8 & 28.6 & 57.1 & 61.9 & 66.7 \\
\hline Percentage of RIL-Yr64/Yr15 1B (\%) & 0 & 100.0 & 100.0 & 95.2 & 95.2 & 90.5 & 85.7 & 85.7 & 85.7 & 81.0 & 81.0 & 81.0 & 76.2 & 71.4 & 42.9 & 38.1 & 33.3 \\
\hline Stripe rust test & \multicolumn{17}{|c|}{ Infection type } \\
\hline PSTv-11 & 8 & 0 & 0 & 0 & 0 & 0 & 0 & 0 & 0 & 0 & 0 & 0 & 0 & 0 & 0 & 0 & 0 \\
\hline PSTv-14 & 8 & 0 & 0 & 0 & 0 & 0 & 0 & 0 & 0 & 0 & 0 & 0 & 0 & 0 & 0 & 0 & 0 \\
\hline PSTV-51 & 8 & 0 & 0 & 0 & 0 & 0 & 0 & 0 & 0 & 0 & 0 & 0 & 0 & 0 & 0 & 0 & 0 \\
\hline Field & 8 & 0 & 0 & 0 & 0 & 0 & 0 & 0 & 0 & 0 & 0 & 0 & 0 & 0 & 0 & 0 & 0 \\
\hline
\end{tabular}

56 Plant Disease / Vol. 103 No. 1 
breeding purposes. The lines that have a longer AvS 1B chromosomal segment may have a less linkage drag problem.

\section{Discussion}

Pyramiding genes from different chromosomes has been widely used to develop cultivars with improved disease resistance, but combining genes into a single chromosome or the same chromosome arm has rarely been attempted. In the present study, we first developed a wheat line by crossing a wheat line carrying $\operatorname{Yr} 64$ and another wheat line carrying $\mathrm{Yr} 15$; both were previously mapped to the short arm of chromosome 1B (Cheng et al. 2014; Mandoulakani et al. 2015). This line presumably carries both genes as it was more resistant than either parent as a result of selection with the tightly linked markers. To prove the line really carries the two genes, we crossed it to AvS and developed an $\mathrm{F}_{4}$ population. By phenotyping and genotyping the population, we validated the presence of both genes in the line RIL-Yr64/Yr15. As this line carries more and longer chromosomal segments from the $\mathrm{Yr} 15$ line and fewer and shorter segments from the Yr64 line, it may have a linkage drag problem of more undesirable genes. To reduce this potential problem, we finally selected $15 \mathrm{~F}_{5}$ lines from the cross AvS $\times$ RILYr64/Yr15. All of these lines carry the Xbarc8-239 - Yr15 Xgwm413-102 - Yr64 - Xgwm273-194 chromosomal region, but with various portions of 1B chromosome from RIL-Yr64/Yr15 or AvS (Table 2). To our knowledge, this study is the first to pyramid two effective stripe rust resistance genes on the same chromosome into single wheat lines. These lines should be more useful for incorporating $\mathrm{Yr} 15$ and $\operatorname{Yr} 64$ together into more wheat cultivars.

In this study, we focused on developing wheat lines with $\mathrm{Yr} 15$ and Yr64 on chromosome 1B and therefore used markers along chromosome $1 \mathrm{~B}$ to confirm the pyramided gene region. The presences of SSR marker allele Xbarc8-239 from AvSYr15NIL in the originally selected RIL-Yr64/Yr15 and the finally selected $15 \mathrm{~F}_{5}$ lines from the AvS $\times$ RIL-Yr64/Yr15 cross indicate Yr15 in these lines. Similarly, the presence of the Xgwm413-102 allele indicates $Y r 64$ in these selected lines. Interestingly, the majority of the chromosome $1 \mathrm{~B}$ in the original selected line RIL-Yr64/Yr15 was from AvSYr15NIL (Fig. 5), although RIL-Yr64 was used as the female parent in the cross of RIL-Yr64 × AvSYr15NIL to develop RIL-Yr64/Yr15. Some parts of chromosome 1B in RIL-Yr64/Yr15 was from the $\mathrm{Yr} 15$ wild emmer wheat donor and the large portion of the remaining chromosome should come from the common wheat line V763-251-wb, which was derived from T. turgidum subsp. dicoccoides and was used in the development of AvSYr15NIL (Wellings and McIntosh 1998; Wellings et al. 2009). The large number of different marker alleles along chromosome 1B between AvS and AvSYr15NIL (AvS*6/Yr15) indicates that AvSYr15NIL has a large proportion of chromosome 1B from the hexaploid wheat donor, although it has been developed through a sixtime backcrossing procedure (Fig. 5). However, in the present study, we were able to increase the AvS 1B chromosome segments to up to $68.2 \%$. As Avocet is a commonly grown bread wheat cultivar in Australia and widely adapted to most spring wheat growing regions in the world (Wellings et al. 2009), the selected wheat lines carrying both Yr15 and Yr64 with larger portions of the AvS chromosome 1B should have more advantages in breeding programs.

A minor QTL on chromosome 1B was identified only in the seedling test with Pst race PSTv-11. This QTL was much less effective than the Yr15-Yr64 region, but its LOD value was greater than the 3.0 threshold (Fig. 4). This QTL was between SSR markers $X w m c 216$ and Xwmc156 with the peak close to Xgwm131. Based on the resistance alleles of these markers, the minor QTL was likely from AvSYr15NIL and transgressed into the RIL-Yr64/Yr15 line. Because of its small effect and not effective against other races, the QTL is not useful in breeding programs.

Linkage drag is a major concern in utilizing stripe rust resistance or any other traits in wheat breeding. For example, the linkage between the flour quality defect and the gene cluster containing $\operatorname{Yr} 9, \operatorname{Lr} 26$, and $\mathrm{Sr} 31$ for resistance to stripe rust, leaf rust, and stem rust, respectively in the $1 \mathrm{~B} / 1 \mathrm{R}$ wheat-rye translocation has limited the use of the resistance genes in some regions of the world, especially the U.S. Pacific Northwest (Allan 2014; Chen 2013; Naruoka et al. 2015). As Yr15 was originally from wild emmer wheat and Yr64 from durum wheat, wheat lines with pyramided Yr15 and Yr64 may have packed undesirable genes on chromosome 1B. As discussed above, some of the 15 selected $\mathrm{F}_{5}$ lines from the AvS $\times$ RIL-Yr64/Yr15 have increased the AvS chromosome 1B segment or reduced the AvSYr15NIL segment. All of the selected lines had short segments from RIL-Yr64. Thus, the selected lines should have reduced linkage drag compared with previously developed single-gene lines for $\operatorname{Yr} 15$ and $\operatorname{Yr} 64$. The selected $\mathrm{F}_{5}$ lines have different AvS and RIL-Yr64/Yr15 segments out of the Yr15-Yr64 segment. Further work is needed to agronomically characterize these lines, and such work can be incorporated into breeding for selection of different cultivars for different purposes. Choosing from these selected lines as Yr15-Yr64 sources may reduce linkage drag. Further studies can be conducted to identify genes within 10 $\mathrm{cM}$ of the chromosomal region covering $\operatorname{Yr15}$-Yr64. Nevertheless, the $\operatorname{Yr} 15-Y r 64$ lines developed in the present study should be much more useful than the previously developed lines carrying each of these genes separately. It will be better to combine the two genes of high-level, all-stage resistance with non-race specific HTAP resistance through backcrossing and/or other breeding approaches using marker-assisted selection.

\section{Literature Cited}

Allan, R. E. 2014. Club Wheat. Robert E. Allan (self-published), Pullman, WA ISBN 978-1-4951-0549-4 I-V.

Bariana, H. S., Brown, G. N., Bansal, U. K., Miah, H., Standen, G. E., and Lu, M. 2007. Breeding triple rust resistant wheat cultivars for Australia using conventional and marker-assisted selection technologies. Aust. J. Agric. Res. 58:576-587.

Chemayek, B., Bansal, U. K., Qureshi, N., Zhang, P., Wagoire, W. W., and Bariana, H. S. 2017. Tight repulsion linkage between Sr36 and Sr39 was revealed by genetic, cytogenetic and molecular analyses. Theor. Appl. Genet. 130:587-595.

Chen, X. M. 2005. Epidemiology and control of stripe rust [Puccinia striiformis $\mathrm{f}$. sp. tritici] on wheat. Can. J. Plant Pathol. 27:314-337.

Chen, X. M. 2013. Review article: high-temperature adult-plant resistance, key for sustainable control of stripe rust. Am. J. Plant Sci. 4:608-627.

Chen, X. M. 2014. Integration of cultivar resistance and fungicide application for control of wheat stripe rust. Can. J. Plant Pathol. 36:311-326.

Chen, X. M., and Kang, Z. S. 2017. Introduction: history of research, symptoms, taxonomy of the pathogen, host range, distribution, and impact of stripe rust. Pages 1-33 in: Stripe Rust. X. M. Chen and Z. S. Kang, eds. Springer, Dordrecht, The Netherlands.

Chen, X. M., and Line, R. F. 1992. Inheritance of stripe rust resistance in wheat cultivars used to differentiate races of Puccinia striiformis in North America. Phytopathology 82:633-637.

Chen, X. M., Penman, L., Wan, A. M., and Cheng, P. 2010. Virulence races of Puccinia striiformis f. sp. tritici in 2006 and 2007 and development of wheat stripe rust and distributions, dynamics, and evolutionary relationships of races from 2000 to 2007 in the United States. Can. J. Plant Pathol. 32:315-333.

Cheng, P., Xu, L. S., Wang, M. N., See, D. R., and Chen, X. M. 2014. Molecular mapping of genes Yr64 and Yr65 for stripe rust resistance in hexaploid derivatives of durum wheat accessions PI 331260 and PI 480016. Theor. Appl. Genet. 127:2267-2277.

Cox, T. S., Raupp, W. J., and Gill, B. S. 1994. Leaf rust-resistance genes Lr41, Lr42, and Lr43 transferred from Triticum tauschii to common wheat. Crop Sci. 34:339-343.

Gahan, L. J., Ma, Y. T., Cobble, M. L., Gould, F., Moar, W. J., and Heckel, D. G. 2005. Genetic basis of resistance to Cry 1 Ac and Cry2Aa in Heliothis virescens (Lepidoptera: Noctuidae). J. Econ. Entomol. 98:1357-1368.

Gerechter-Amitai, Z. K., Silfhout, C. H., Gramal, A., and Kleitman, F. 1989. Yr15a new gene for resistance to Puccinia striiformis in Triticum dicoccoides sel. G25. Euphytica 43:187-190.

Hou, L., Chen, X. M., Wang, M. N., See, D. R., Chao, S. M., Bulli, P., and Jing, J. X. 2015. Mapping a large number of QTL for durable resistance to stripe rust in winter wheat Druchamp using SSR and SNP markers. PLoS One 10:e0126794.

Jackson, R. E., Bradley, J. R., and Van Duyn, J. W. 2003. Field performance of transgenic cottons expressing one or two Bacillus thuringiensis endotoxins against bollworm, Helicoverpa zea (Boddie). J. Cotton Sci. 7:57-64.

Line, R. F. 2002. Stripe rust of wheat and barley in North America: A retrospective historical review. Annu. Rev. Phytopathol. 40:75-118.

Line, R. F., and Chen, X. M. 1995. Successes in breeding for and managing durable resistance to wheat rusts. Plant Dis. 79:1254-1255.

Line, R. F., and Qayoum, A. 1992. Virulence, aggressiveness, evolution, and distribution of races of Puccinia striiformis (the cause of stripe rust of wheat) in North America 1968-87. Technical Bulletin Number 1788, USDA-ARS Washington, DC.

Liu, L., Wang, M. N., Feng, J. Y., See, D. R., Chao, S. M., and Chen, X. M. 2018. Combination of all-stage and high-temperature adult-plant resistance QTL 
confers high level, durable resistance to stripe rust in winter wheat cultivar Madsen. Theor. Appl. Genet. 131:1835-1849.

Liu, T. L., Wan, A. M., Liu, D. C., and Chen, X. M. 2017. Changes of races and virulence genes of Puccinia striiformis $\mathrm{f}$. sp. tritici, the wheat stripe rust pathogen, in the United States from 1968 to 2009. Plant Dis. 101:1522-1532.

Mandoulakani, B. A., Yaniv, E., Kalendar, R., Raats, D., Bariana, H. S., Bihamta, M. R., and Schulman, A. H. 2015. Development of IRAP-and REMAP-derived SCAR markers for marker-assisted selection of the stripe rust resistance gene Yr15 derived from wild emmer wheat. Theor. Appl. Genet. 128:211-219.

Murphy, L. R., Santra, D., Kidwell, K., Yan, G. P., Chen, X. M., and Campbell, K. G. 2009. Linkage maps of wheat stripe rust resistance genes $Y r 5$ and Yr15 for use in marker-assisted selection. Crop Sci. 49:1786-1790.

Naruoka, Y., Garland-Campbell, K. A., and Carter, A. H. 2015. Genome-wide association mapping for stripe rust (Puccinia striiformis $\mathrm{f}$. sp. tritici) in US Pacific Northwest winter wheat (Triticum aestivum L.). Theor. Appl. Genet. 128:1083-1101.

Peng, J. H., Fahima, T., Röder, M. S., Huang, Q. Y., Dahan, A., Li, Y. C., Grama, A., and Nevo, E. 2000. High-density molecular map of chromosome region harboring stripe-rust resistance genes $\mathrm{YrH} 52$ and $\mathrm{Yr} 15$ derived from wild emmer wheat, Triticum dicoccoides. Genetica 109:199-210.

Qayoum, A., and Line, R. F. 1985. High-temperature, and adult-plant resistance to stripe rust of wheat. Phytopathology 75:1121-1125.

Riede, C., and Anderson, J. 1996. Linkage of RFLP markers to an aluminum tolerance gene in wheat. Crop Sci. 36:905-909.

Schneider, A. 2002. Mapping of a nodulation loci sym 9 and sym10 of pea. Theor. Appl. Genet. 104:1312-1316.

Shi, A. N., Chen, P. Y., Li, D. X., Zheng, C. M., Zhang, B., and Hou, A. F. 2009. Pyramiding multiple genes for resistance to soybean mosaic virus in soybean using molecular markers. Mol. Breed. 23:113.

Singh, A., Pandey, M. P., Singh, A. K., Knox, R. E., Ammar, K., Clarke, J. M., Clarke, F. R., Singh, R. P., Pozniak, C. J., DePauw, R. M., McCallum, B. D., Cuthbert, R. D., Randhawa, H. S., and Fetch, J. T. G. 2013. Identification and mapping of leaf, stem and stripe rust resistance quantitative trait loci and their interactions in durum wheat. Mol. Breed. 31:405-418.

Somers, D. J., Isaac, P., and Edwards, K. 2004. A high-density microsatellite consensus map for bread wheat (Triticum aestivum L.). Theor. Appl. Genet. 109:1105-1114
Voorrips, R. E. 2002. MapChart: Software for the graphical presentation of linkage maps and QTLs. J. Hered. 93:77-78.

Wan, A. M., and Chen, X. M. 2014. Virulence characterization of Puccinia striiformis f. sp. tritici using a new set of $Y r$ single-gene line differentials in the United States in 2010. Plant Dis. 98:1534-1542.

Wan, A. M., Chen, X. M., and Yuen, J. 2016. Races of Puccinia striiformis f. sp. tritici in the United States in 2011 and 2012 and comparison with races in 2010 Plant Dis. 100:966-975

Wang, M. N., and Chen, X. M. 2017. Stripe rust resistance. Pages 353-558 in Stripe Rust. X. M. Chen and Z. S. Kang, eds. Springer, Dordrecht, The Netherlands.

Wang, S., Wong, D., Forrest, K., Allen, A., Chao, S., Huang, B. E., Maccaferri, M., Salvi, S., Milner, S. G., and Cattivelli, L. 2014. Characterization of polyploid wheat genomic diversity using a high-density 90,000 single nucleotide polymorphism array. Plant Biotechnol. J. 12:787-796.

Wellings, C. R. 2011. Global status of stripe rust: a review of historical and current threats. Euphytica 179:129-141.

Wellings, C. R., and McIntosh, R. A. 1998. Host-pathogen studies of wheat stripe rust in Australia. Pages 336-338 in: Proc. of the 9th Int. Wheat Genetics Symp., Saskatoon, 2-7 Aug. 1998. Vol. 3. A.E. Slinkard, ed. University Extension Press, Univ. of Saskatchewan, Saskatoon, SK, Canada.

Wellings, C. R., Singh, R. P., Yahyaoui, A. H., Nazari, K., and McIntosh, R. A 2009. The development and application of near-isogenic lines for monitoring cereal rust pathogens. Pages 77-87 in: Oral Papers 2009 Technical Workshop. New York. https://www.globalrust.org/sites/default/files/posters/ wellings_2009.pdf

Werner, K., Friedt, W., and Ordon, F. 2005. Strategies for pyramiding resistance genes against the barley yellow mosaic virus complex (BaMMV, BaYMV, BaYMV-2). Mol. Breed. 16:45-55.

Yaniv, E., Raats, D., Ronin, Y., Korol, A. B., Grama, A., Bariana, H., Dubcovsky, J., and Schulman, A. H. 2015. Evaluation of marker-assisted selection for the stripe rust resistance gene $Y r 15$, introgressed from wild emmer wheat. Mol Breed. 35:43.

Yasuda, N., Mitsunaga, T., Hayashi, K., Koizumi, S., and Fujita, Y. 2015. Effects of pyramiding quantitative resistance genes pi21, Pi34, and Pi35 on rice leaf blast disease. Plant Dis. 99:904-909. 